\title{
ARTICLES
}

\section{DNA Microarray Reveals Novel Genes Induced by Mechanical Forces in Fetal Lung Type II Epithelial Cells}

\author{
YULIAN WANG, BENJAMIN S. MACIEJEWSKI, GAIA WEISSMANN, OPHIRA SILBERT, HILLARY HAN, AND \\ JUAN SANCHEZ-ESTEBAN
}

\begin{abstract}
Department of Pediatrics [Y.W., B.S.M., G.W., O.S., J.S.-E.], Division of Neonatology, Women \& Infants Hospital of Rhode Island, Providence, Rhode Island, 02905; Department of Community Health [H.H.], Center for Statistical Sciences, Brown University, Providence, Rhode Island, 02912
\end{abstract}

\begin{abstract}
Mechanical forces are essential for normal fetal lung development. However, the cellular and molecular mechanisms regulating this process are still poorly defined. In this study, we used oligonucleotide microarrays to investigate gene expression in cultured embryonic d 19 rat fetal lung type II epithelial cells exposed to a level of mechanical strain similar to the developing lung. Significance Analysis of Microarrays (SAM) identified 92 genes differentially expressed by strain. Interestingly, several members of the solute carrier family of amino acid transporter (Slc7a1, Slc7a3, Slc6a9, and tumor-associated protein 1) genes involved in amino acid synthesis (Phgdh, Psat1, Psph, Cars, and Asns), as well as the amiloride-sensitive epithelial sodium channel gene (Scnn1a) were up-regulated by the application of force. These results were confirmed by quantitative real-time PCR (qRT-PCR). Thus, this study identifies genes induced by strain that may be important for amino acid signaling pathways and protein synthesis in fetal type II cells. In addition, these data suggest that mechanical forces may contribute to facilitate lung fluid reabsorption in preparation for birth. Taken together, the present investigation provides further insights into how mechanical forces may modulate fetal lung development. (Pediatr Res 60: 118-124, 2006)
\end{abstract}

$\mathrm{N}^{\circ}$ ormal lung growth and development during fetal life are critical for extrauterine survival. Premature infants are often born before sufficient lung maturation has occurred, and, as a result, they experience a high rate of long-term pulmonary complications such as bronchopulmonary dysplasia. Understanding the mechanisms of prenatal lung growth and development is a crucial step for the design of preventive and therapeutic strategies.

Mechanical forces generated in utero by repetitive breathing movements and by fluid distension are essential to mammalian lung development (1-3). Previous in vitro experiments have demonstrated that application of force to cultured type II

Received January 11, 2006; accepted March 14, 2006.

Correspondence: Juan Sanchez-Esteban, M.D., Department of Pediatrics, Women \& Infants Hospital, 101 Dudley Street, Providence, RI 02905; e-mail: jsanchezesteban@wihri.org

This work was supported by National Institutes of Health grants RR018728 and RR015578. J.S.-E. is a Parker B. Francis Fellow in Pulmonary Research. epithelial cells induces cell proliferation (4) and differentiation (5). Other studies have begun to identify mechanoreceptors and cell signaling pathways mediating fetal lung growth and maturation (4-8). However, the precise molecular and cellular mechanisms by which lung cells sense mechanical stimuli to influence lung development are still poorly defined.

DNA microarray technology provides a powerful tool for rapid, comprehensive, and quantitative analysis of gene expression profile. This technique has been previously used to assess changes in gene expression in endothelial cells (9), bladder smooth muscle cells (10), and human pulmonary A549 (11) and H441 (12) epithelial cells exposed to mechanical strain.

Therefore, the goal of the present study was to identify genes differentially expressed by mechanical stress of fetal type II epithelial cells. We used an in vitro model system in which embryonic d (E) 19 type II cells are exposed to mechanical forces similar to that observed in the developing lung. These studies revealed that mechanical forces induce genes related to amino acid transporter, amino acid synthesis, and sodium transport across the cell membrane.

\section{METHODS}

Cell isolation and mechanical distention protocol. Fetal rat lungs were obtained from timed-pregnant Sprague-Dawley rats (Charles Rivers, Wilmington, MA) and E19 type II cells were isolated as previously described (6). Epithelial cells were then seeded onto Bioflex plates precoated with collagen-1 (Flexcell Corporation, Hillsborough, NC) and maintained in serum-free Dulbecco's modified Eagle's medium (DMEM) for $24 \mathrm{~h}$. Plates containing adherent cells were mounted in a Flexercell FX-4000 Strain Unit (Flexcell Corp.). Equibiaxial elongation of 5\% was applied at intervals of 60 cycles per minute for $15 \mathrm{~min}$ plus $2.5 \%$ continuous distention for the remaining $45 \mathrm{~min}$ of each hour, for $16 \mathrm{~h}$. This regimen was chosen to simulate mechanical forces experienced by type II epithelial cells during lung development (13), and it is

Abbreviations: ENaC, amiloride-sensitive epithelial sodium channel; qRTPCR, quantitative real-time PCR; SAM, Significance Analysis of Microarrays 
based on previous studies from our laboratory $(5,8)$. Cells grown on nonstrained substrates were treated in an identical manner and served as controls.

Affymetrix GeneChip Analysis. Total RNA was extracted from E19 type II cells using TRIzol reagent according to the manufacturer's instructions (Invitrogen, Carlsbad, CA) and purified further using the Rneasy Mini Kit (Invitrogen). Five micrograms of total RNA was used for the synthesis of labeled target in the Center for Genomic and Proteomics, Brown Medical School. Briefly, RNA was reverse-transcribed into cDNA using the Superscript Double Stranded cDNA Synthesis Kit (Invitrogen) with a T7-(dT)24 oligomer to prime the first-strand synthesis. DNA polymerase and DNA ligase were included in the synthesis of the second strand. After phase lock gel phenol/chloroform cDNA extraction and ethanol precipitation, conversion of double-stranded cDNA into biotin-labeled cRNA was accomplished using the BioArray High Yield RNA Transcript Labeling kit (T7) (Enzo Diagnostics, Farmingdale, NY) according to the manufacturer's instructions. Following in vitro transcription reactions purification and RNA cleanup, fragmentation of the labeled cRNA for target preparation was done according to the Affymetrix GeneChip Expression Analysis Protocol. After hybridization cocktails preparation, the Affymetrix rat E230A GeneChip array was hybridized with the fragmented labeled cRNA for $16 \mathrm{~h}$ at $45^{\circ} \mathrm{C}$ as described in the Affymetrix Technical Analysis Manual. GeneChip arrays were then loaded into the Affymetrix GeneChip Fluidics Station 400 for washing and staining, following the appropriate Affymetrix fluidics protocol. GeneChips were then scanned using the Agilent Technologies G2500A GeneArray Scanner (Agilent Technologies, Palo Alto, CA).

Microarray data analysis. Prior to analysis, data generated from the six hybridizations (three pairs from control and strain samples, using different litters for each pair) were processed using Microarray Suite software, version 5.0 , to yield signal values. These expression values were calculated from the combined, background-adjusted "perfect match" and "mismatch" for each probe set, using a statistical algorithm described in Affymetrix Statistical Manual. Hybridization data have been submitted to the National Center for Biotechnology Information (NCBI) Gene Expression Omnibus database (GEO) (http://www.ncbi.nlm.nih.gov/geo) with GEO accession number GSE3541. To allow for comparison of signal intensity across arrays, the data were first normalized by adjusting expression values according to average percentiles (quantile normalization). In addition, to reduce noise, certain genes were eliminated from subsequent analysis, including those with low expression levels $(<200$ on all chips), genes with invariant changes [(control - strain) in absolute value $<50$ of all three pairs] and genes with contradictory changes of direction during the repeated experiments. In total, around $75 \%$ of genes were filtered, leaving 2030 genes for further analysis.

To identify fetal type II cell genes that were differentially expressed in response to mechanical strain, the SAM statistical method (14) was used. In SAM analysis, each gene is assigned a numerical score (d) that is derived from the change in gene expression relative to the SD of repeated measurements across data sets. For genes with score greater than an adjustable threshold, SAM uses permutations of the repeated measurements to estimate the percentage of genes identified by chance, the False Discovery Rate. SAM analysis was performed on paired, unlogged data with eight blocked permutations. As an additional control, a fold change cutoff value of 1.5 was selected.

Validation of gene expression changes by real-time PCR. Real-time PCR (qRT-PCR) was performed on 12 genes to verify microarray results. Predesigned TaqMan primers were purchased from Assays-on-Demand Gene Expression Products (Applied Biosystems, Foster City, CA). Standard curves were generated for each primer set and housekeeping gene $18 \mathrm{~S}$ ribosomal RNA. Linear regression revealed efficiencies between 96 and $99 \%$. Therefore, fold expressions of strained samples relative to controls were calculated using the $\Delta \Delta \mathrm{C}_{\mathrm{T}}$ method for relative quantification (RQ). Samples were normalized to the $18 \mathrm{~S}$ rRNA. No differences in RQ values for $18 \mathrm{~S}$ were found between control and strain samples. Three micrograms of total RNA extracted from strained and control E19 type II cells were reverse-transcribed into cDNA using the ¡Script cDNA Synthesis Kit (Bio-Rad, Hercules, CA) according to the manufacturer's instructions. To amplify the cDNA by qRT-PCR, $5 \mu \mathrm{L}$ of the resulting cDNA were added to a mixture of $25 \mu \mathrm{L}$ of TaqMan Universal PCR Master Mix (Applied Biosystems) and $2.5 \mu \mathrm{L}$ of $20 \times$ Assays-onDemand Gene Expression Assay Mix containing forward and reverse primers and TaqMan-labeled probe (Applied Biosystems). The reactions were performed in an ABI Prism 7000 Sequence Detection System (Applied Biosystems). All assays were performed in triplicate.

Statistical analysis. Paired $t$ test was used to compare RQ values obtained from qRT-PCR from E19 type II epithelial cells exposed or not to mechanical strain for $16 \mathrm{~h}$. A level of $p<0.05$ was considered significant.

\section{RESULTS}

Data normalization and SAM analysis. Before statistical analysis, raw data were normalized. Normalization removes nonbiological systematic variations across chips. Figure $1 A$ shows box plots of the six arrays (three pairs of control and strain samples) before and after quantile normalization, side by side. Before normalization, the second and fourth arrays showed slightly longer range of expressions (stretched boxes) than the others. Normalization scaled the data, so the medians, quartiles, and range were now equal for all six arrays. Figure $1 B$ shows bivariate plots of control and strain for nonnormalized and normalized expressions. The data points cluster around the 45 degree line, indicating that most genes are expressed at similar levels in both groups. After the data were normalized and filtered, SAM statistical software was used to identify genes in which their expression levels differed significantly between control and strain samples. Using a threshold value of 0.735 , we identified 92 genes (63 up-regulated and 29 down-regulated) out of 2030 to be differentially expressed by 1.5-fold or greater in E19 type II cells exposed to mechanical strain. The false discovery rate was $11.9 \%$ (Fig. 2). These genes are listed in Tables 1 and 2, along with their output scores, fold change, and $q$ values, and ordered by their functions.
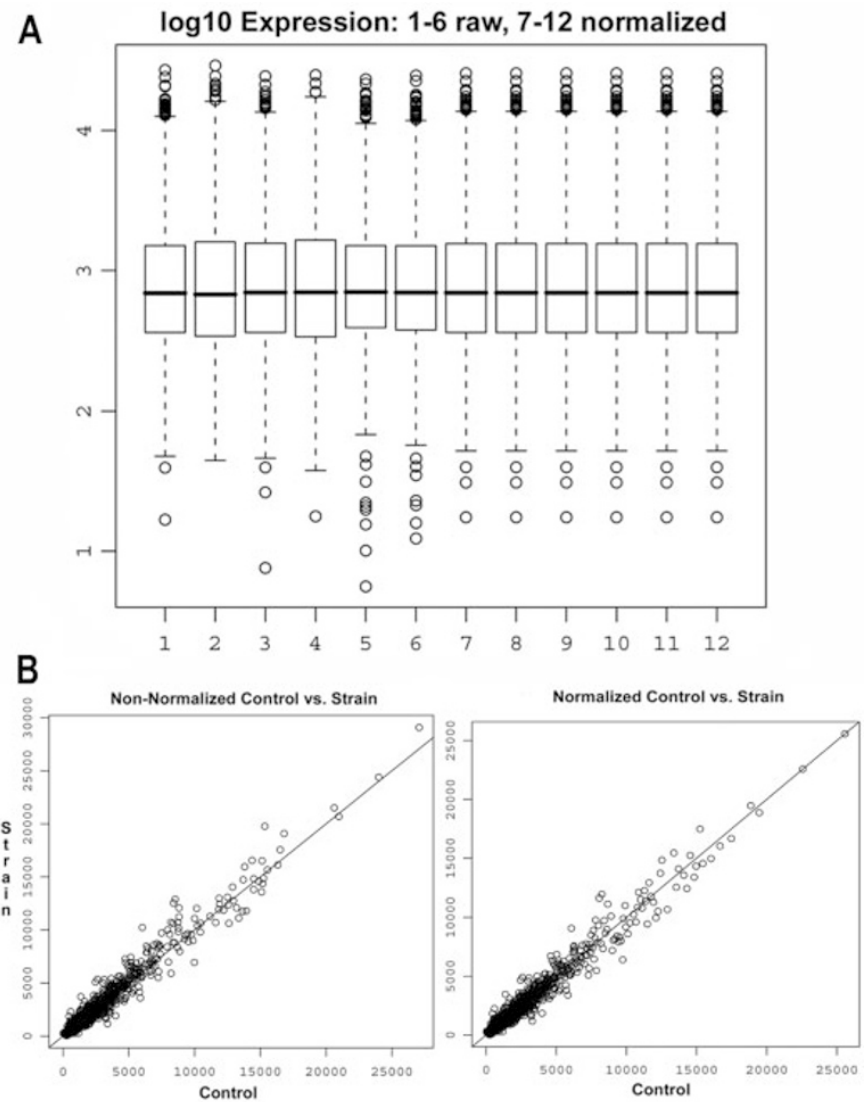

Figure 1. Normalization of the microarray data and SAM analysis. (A) Box plots of non-normalized (arrays 1-6) and normalized expressions (7-12). (B) Bivariate plots for control and strain expressions before and after normalization. The expression values depicted are for the first array pair. 


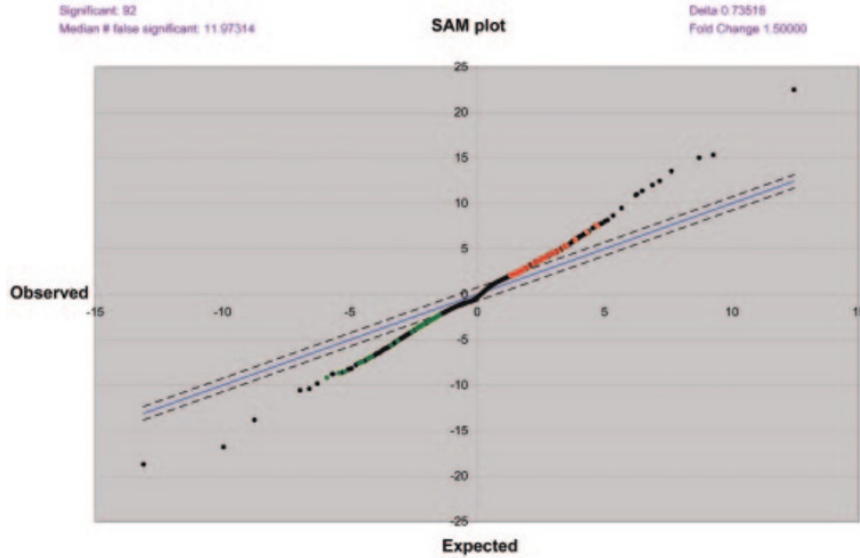

Figure 2. SAM graph plot of expected $v s$ observed values of expression. The dotted lines parallel to 45 degree mark the boundary of the chosen threshold value $(0.73516)$. The genes outside this threshold were selected as significantly expressed genes. A total of 92 genes, 43 up-regulated (in red) and 16 down-regulated (in green), out of 2030 were identified to be differentially expressed by 1.5 -fold or greater in E19 type II cells exposed to mechanical strain. The false discovery rate was $11.9 \%$.

The results of some of the genes potentially relevant to fetal lung development are discussed below according to their functional categories.

Mechanical strain of fetal type II cells regulates the expression of genes related to amino acid transport and synthesis. Microarray analysis identified a group of genes related to amino acid transport and amino acid synthesis significantly increased by strain. The cationic amino acid transporters $\mathrm{y}^{+}$system, solute carrier family 7 , member 1 (Slc7a1) and solute carrier family 7, member 3 (Slc7a3) (L-arginine and L-lysine transport) increased by $1.72-$ and 2 -fold, respectively. Solute carrier family 6, member 9 (Slc6a9), involved in glycine transport, increased by 1.74fold. Similarly, Slc7a5 (tumor-associated protein 1), another cationic amino acid transporter highly expressed during liver development (15) increased by 2 -fold (Table 1). The upregulation of these genes by strain was confirmed by qRTPCR (Fig. 3). Slc3a2, a dibasic and neutral amino acid transporter that increased after $16 \mathrm{~h}$ of strain by microarray analysis did not change by qRT-PCR (Fig. 3).

Our studies also revealed strain-mediated up-regulation of genes involved in L-serine biosynthesis, including 3-phosphoglycerate dehydrogenase (Phgdh) (1.69-fold), phosphoserine aminotransferase (Psat1) (1.67-fold), and phosphoserine phosphatase (Psph) (1.7-fold). Likewise, cysteinyl-tRNA synthetase (Cars, cysteine biosynthesis) increased by 1.8 -fold and asparagine synthetase (Asns, asparagine biosynthesis) increased by 1.85 -fold (Table 1 ). Microarray results were confirmed by qRT-PCR (Fig. 4). Taken together, these studies demonstrate that mechanical strain is a potent stimulus for induction of amino acid transporter and amino acid synthesis genes in fetal lung type II epithelial cells.

Mechanical strain modulates sodium transport across the type II cell membrane. In the current study, E19 fetal type II epithelial cells exposed to mechanical strain for $16 \mathrm{~h}$ showed up-regulation of the sodium channel nonvoltage-gated, type I, alpha polypeptide (Scnn1a) gene by 2.1 -fold (Table 1). This amiloride-sensitive epithelial sodium channel $(\mathrm{ENaC})$ gene modulates $\mathrm{Na}^{+}$transport across the cell membrane and is critical to facilitate lung fluid reabsorption around birth (16). These results were validated by qRT-PCR (Fig. 5). Another ion transport gene, solute carrier family 19 , member 1 (Slc19a1), involved in $\mathrm{Na}^{+} / \mathrm{H}^{+}$exchanger and folate transport, up-regulated by microarray analysis could not be confirmed by qRT-PCR (Fig. 5).

Other genes differentially expressed by mechanical strain of fetal type II epithelial cells. SAM analysis identified genes induced by strain that participate in the $\mathrm{Wnt} / \beta$-catenin signaling pathway, including Fos-like antigen 1 (Fosl1), a transcription factor of the fos-related family genes (by 1.65 -fold) and the seven in absentia 2 gene (sina), required for eye development in Drosophila (by 1.83-fold) (17).

Tissue remodeling by programmed cell death or apoptosis is important for normal lung morphogenesis (18). Our data show that mechanical strain differentially expresses genes involved in apoptosis, including ubiquitin-like domain member 1 (3.1-fold), DNA-damage inducible transcript 3 (1.87fold), heme oxygenase 1 (1.87-fold), and transglutaminase 2 (0.57-fold) (Tables 1 and 2).

Several other genes participating in metabolism (bilirubin conjugation, nucleotide and nucleic acid metabolism, methyltransferase activity, gluconeogenesis, cholesterol biosynthesis, proteolysis), signaling (MAPK activation, protein phosphorylation and dephosphorylation, calcium signaling, G-proteincoupled receptor, Ras GTPase, zinc ion binding), transcription and translation, electron transport, extracellular matrix/ cytoskeleton, and so on, were also modulated by mechanical forces (Tables 1 and 2).

\section{DISCUSSION}

Although mechanical forces are critical for normal lung development, the mechanisms regulating this process remain to be defined. In the current study, we used DNA microarray technology to assess changes in gene expression of E19 fetal type II epithelial cells exposed to mechanical strain. Our results demonstrate 92 genes that were differentially expressed in response to mechanical forces. Among them, we identified a group of genes not previously described to be modulated by force, including genes related to amino acid transporter, amino acid synthesis and sodium transport across the membrane.

Amino acids are involved in biosynthetic pathways and are essential for metabolic processes (19). They do not permeate cell membranes without specialized transport system carriers. The present study identifies two members (Slc7a1 and Slc7a3) of the arginine transporters activated by strain. L-arginine is a necessary precursor for protein and creatinine biosynthesis and plays a critical role in regulating nitrogen balance. Larginine is metabolized to nitric oxide (NO) and L-citrulline (20). Cyclic strain, inflammatory mediators, growth factors and lysophosphatidylcholine stimulate L-arginine transport in vascular smooth muscle cells $(21,22)$. The significance of our findings in fetal lung development needs to be determined. Strain-induced up-regulation of genes modulating L-arginine 
Table 1. Genes up-regulated by mechanical strain

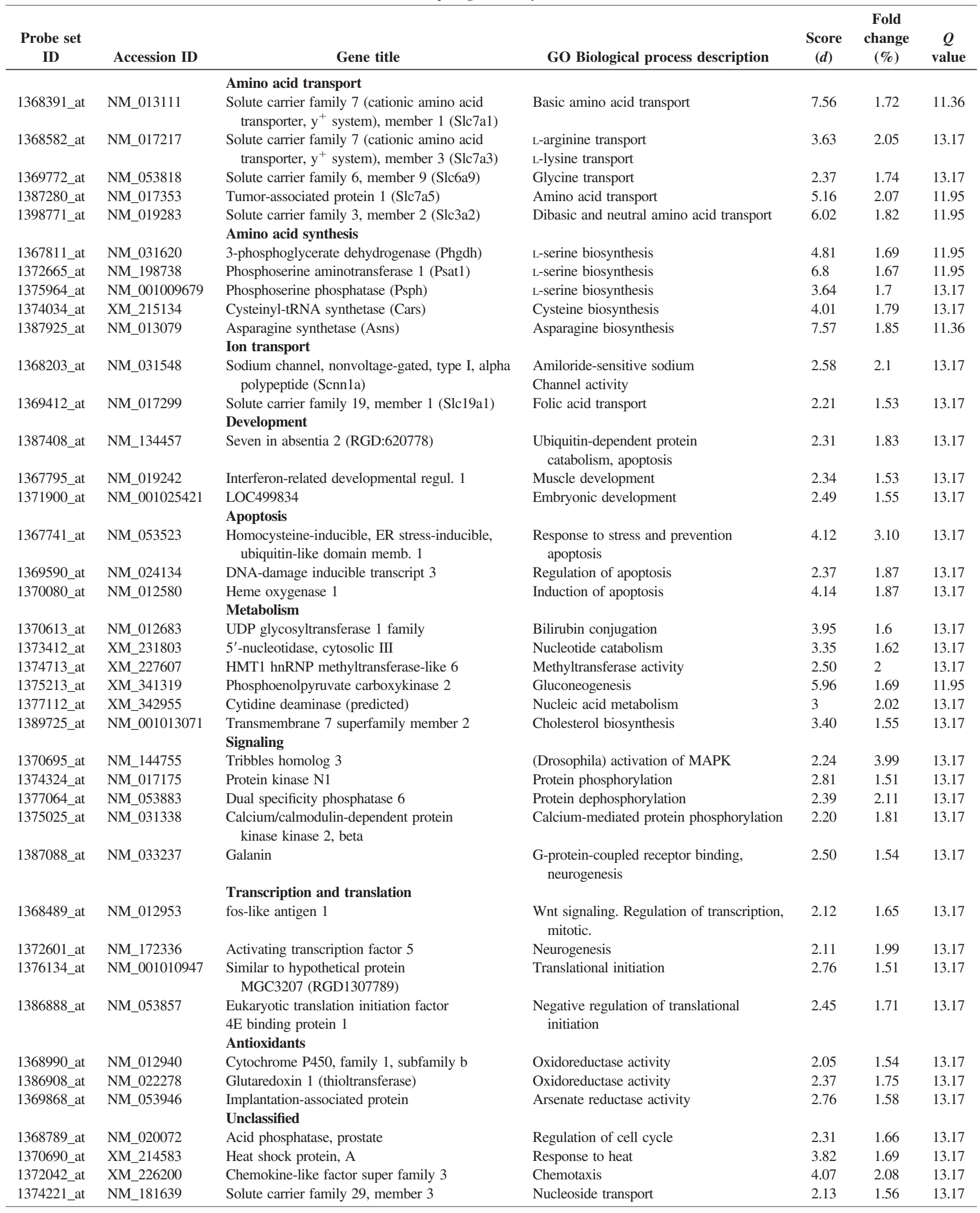

Probe set ID numbers refer to rat E230A GeneChips from Affymetrix. The score $d$ is the relative difference in expression for a particular gene between the control and strain conditions. The qvalue for each gene is the lowest False Discovery Rate at which that gene is called significant. (Note: transcribed loci with unknown functions are not included.) 
Table 2. Genes down-regulated by mechanical strain

\begin{tabular}{|c|c|c|c|c|c|c|}
\hline $\begin{array}{c}\text { Probe set } \\
\text { ID }\end{array}$ & $\begin{array}{l}\text { Accession } \\
\text { ID }\end{array}$ & Gene title & $\begin{array}{c}\text { GO Biological process } \\
\text { description }\end{array}$ & $\begin{array}{c}\text { Score } \\
(d)\end{array}$ & $\begin{array}{c}\text { Fold } \\
\text { change } \\
(\%)\end{array}$ & $\underset{\text { value }}{Q}$ \\
\hline & & Development & & & & \\
\hline 1368522_at & NM_031340 & Timeless homolog (Drosophila) & Branching morphogenesis & -2.41 & 0.62 & 13.17 \\
\hline 1368829_at & NM_031825 & Fibrillin 1 & Skeletal and visual development & -8.65 & 0.58 & 8.76 \\
\hline 1370026_at & NM_012935 & Crystallin, alpha B & Eye development & -4.09 & 0.63 & 13.17 \\
\hline \multirow[t]{2}{*}{ 1375713_at } & NM_024383 & $\begin{array}{l}\text { Hairy and enhancer of split } 5 \\
\text { (Drosophila) }\end{array}$ & $\begin{array}{l}\text { Negative regulation of neuron } \\
\text { differentiation }\end{array}$ & -2.34 & 0.31 & 13.17 \\
\hline & & Transport & & & & \\
\hline 1370239_at & NM_013096 & Hemoglobin alpha, adult chain 1 & Oxygen transport & -3.77 & 0.30 & 13.17 \\
\hline 1372190_at & NM_012825 & Aquaporin 4 & Water transport & -3.02 & 0.57 & 13.17 \\
\hline 1373734_at & NM_177481 & $\begin{array}{l}\text { Solute carrier organic anion } \\
\text { transporter family, member } 3 \mathrm{a} 1\end{array}$ & Ion, prostaglandin transport & -2.35 & 0.56 & 13.17 \\
\hline 1369943_at & NM_019386 & $\begin{array}{l}\text { Apoptosis } \\
\text { Transglutaminase 2, C polypeptide } \\
\text { Metabolism }\end{array}$ & Induction of apoptosis & -7.04 & 0.57 & 11.36 \\
\hline 1373329_at & NM_130424 & Transmembrane protease, serine2 & Proteolysis and peptidolysis & -5.13 & 0.62 & 11.95 \\
\hline \multirow[t]{2}{*}{ 1389470_at } & NM_212466 & B-factor, properdin & $\begin{array}{l}\text { Proteolysis and peptidolysis } \\
\text { complement activation }\end{array}$ & -3.28 & 0.56 & 13.17 \\
\hline & & Signaling & & & & \\
\hline 1374902_at & XM_227396 & $\begin{array}{l}\text { IQ motif containing GTPase } \\
\text { activating protein } 3\end{array}$ & Ras GTPase activator & -2.83 & 0.63 & 13.17 \\
\hline 1373748_at & XM_232226 & $\begin{array}{l}\text { PDZ domain containing RING } \\
\text { finger } 3\end{array}$ & Zinc ion binding, signaling & -7.57 & 0.65 & 8.76 \\
\hline 1367594_at & NM_017087 & $\begin{array}{l}\text { ECM/Cytoskeleton } \\
\text { Biglycan }\end{array}$ & $\begin{array}{l}\text { ECM structural constituent } \\
\text { cytoskeleton organization }\end{array}$ & -2.42 & 0.65 & 13.17 \\
\hline 1369928_at & NM_019212 & Actin, alpha 1 , skeletal muscle & and biogenesis & -2.39 & 0.57 & 13.17 \\
\hline \multirow[t]{2}{*}{ 1370857_at } & M22757 & $\begin{array}{l}\text { Smooth muscle } \\
\text { (RGD:621676) }\end{array}$ & Alpha-actin muscle contraction & -8.48 & 0.64 & 8.76 \\
\hline & & Unclassified & & & & \\
\hline 1367664_at & NM_013220 & $\begin{array}{l}\text { Ankyrin repeat domain } 1 \\
\quad \text { (cardiac muscle) }\end{array}$ & & -9.16 & 0.64 & 8.76 \\
\hline 1367776_at & NM_019296 & Cell division cycle 2 & Homolog A cell cycle, mitosis & -3.61 & 0.62 & 13.17 \\
\hline
\end{tabular}

Probe set ID numbers refer to rat E230A GeneChips from Affymetrix. The score $d$ is the relative difference in expression for a particular gene between the control and strain conditions. The $q$ value for each gene is the lowest False Discovery Rate at which that gene is called significant.

(Note: transcribed loci with unknown functions are not included.)

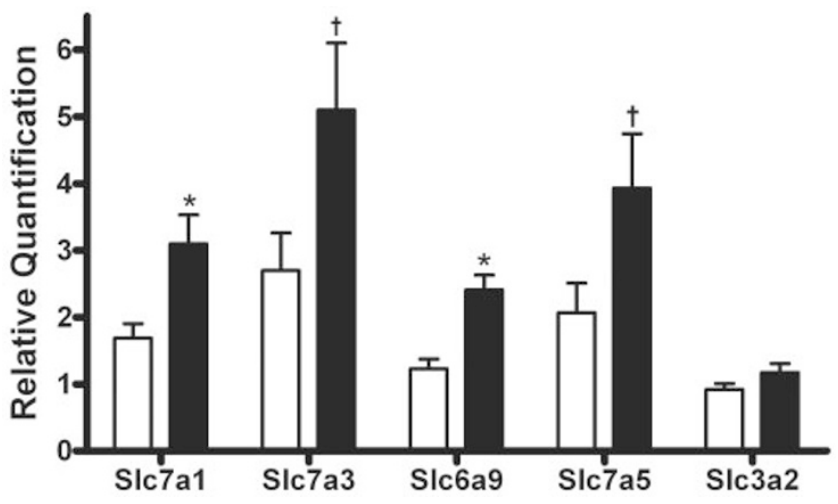

Figure 3. Confirmation of amino acid transporters microarray data by qRTPCR. Type II cells isolated from E19 rat fetal lung were cultured on flexible silastic membranes coated with collagen 1 and then exposed to strain for $16 \mathrm{~h}$ as described in "Methods." Total RNA was reverse-transcribed and the cDNA product was analyzed by $\mathrm{qRT}$-PCR using the $\Delta \Delta \mathrm{C}_{\mathrm{T}}$ method for relative quantification (RQ). Results are the mean \pm SEM from seven different experiments performed in triplicate $\left({ }^{*} p<0.002 ; \dagger p<0.007\right)$. White bars $=$ control; black bars $=$ strain

transport may be important for fetal type II cell protein synthesis and/or for NO production. NO regulates not only pulmonary vascular tone during the perinatal transition but

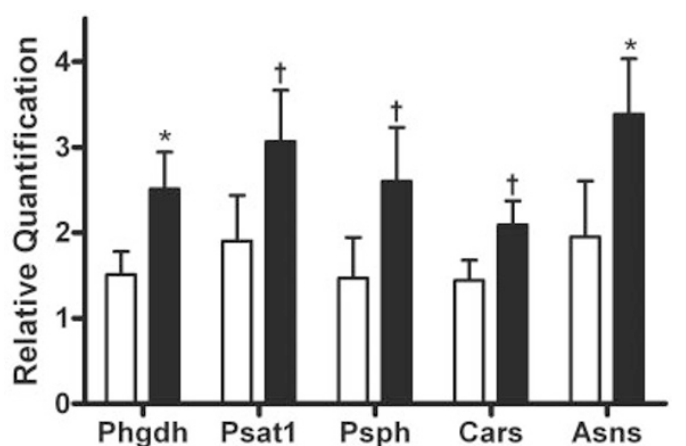

Figure 4. Mechanical strain induces genes involved in amino acid synthesis. qRT-PCR analysis by the $\Delta \Delta \mathrm{C}_{\mathrm{T}}$ method validating the microarray findings. Results are the mean \pm SEM from seven different experiments performed in triplicate $(* p<0.004 ; \dagger p<0.01)$. White bars $=$ control; black bars $=$ strain.

also promotes branching morphogenesis (23), angiogenesis (24), and alveolarization (25). NO is a downstream effector of vascular endothelial growth factor (VEGF). Recent studies indicate that VEGF is essential for normal pulmonary parenchymal development (26). In addition, VEGF is expressed in distal lung epithelial cells and its mRNA and protein levels are increased by mechanical forces (27). These studies support a 


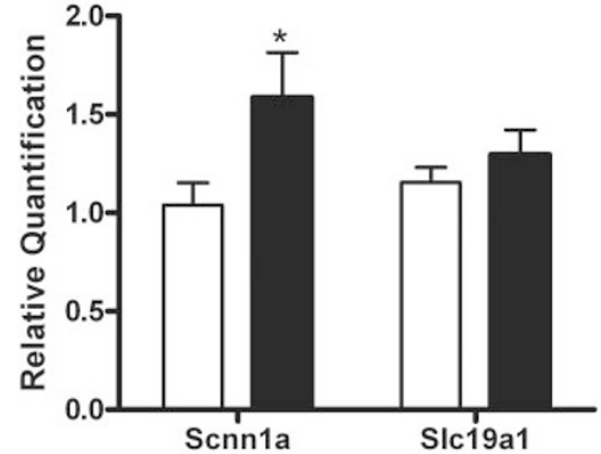

Figure 5. Validation of ion transport microarray findings by qRT-PCR. Graphical depiction of results from seven separate experiments showing that mechanical strain up-regulates the amiloride-sensitive sodium channel gene Scnn1a $\left({ }^{*} p<0.002\right)$. White bars $=$ control; black bars $=$ strain

role for VEGF-NO as an autocrine/paracrine regulator of lung development. In this context, mechanical forces may stimulate fetal lung development by promoting the uptake of L-arginine necessary for NO synthesis.

The biologic role of amino acid transporters during lung development is currently unknown. It has been postulated that apical transepithelial amino acid transporters may play important roles in protein removal from the alveolar space to prevent airway obstruction and bacterial overgrowth in adult lungs (28). However, based on the low protein concentration present in the lumen of the fetal lung, it is unlikely that these transporters are localized on the apical membrane of the fetal type II cells. We hypothesize instead they are present on the basolateral surface to uptake amino acids from bloodstream or surrounding interstitial space required for signaling pathways and protein synthesis.

Although maintenance of a constant transpulmonary pressure in the lumen of the fetal lung by epithelial fluid secretion is essential for normal lung development, reabsorption of these fluids during labor and soon after birth is also critical to survive in an air-breathing environment (29). The critical role of $\mathrm{ENaC}$ in alveolar fluid homeostasis has been highlighted by the fact that newborn $\alpha$-ENaC knockout mice died shortly after birth, primarily from failure to clear their lungs of fluid (16). ENaC subunits are differentially regulated during lung development. The $\alpha$-ENaC subunit is initially detected in $\mathrm{E} 19$ fetal rat type II cells whereas $\beta$ - and $\gamma$-subunits are predominantly expressed after birth (30). Dexamethasone induces $\alpha$-subunit mRNA expression only during the canalicular stage of lung development (E19). This gestational age correlates with an increase in endogenous fetal corticosteroids levels, suggesting that perinatal expression of $\alpha$-ENaC is, at least in part, regulated by corticosteroids (30). Our data provide evidence that mechanical strain may also modulate $\alpha$-ENaC expression to prepare the fetal lung for fluid reabsorption during labor.

Our study has the limitations inherent to an in vitro experimental system in which E19 type II cells are isolated from their environment. Furthermore, cultured type II epithelial cells have been shown to express different phenotype than freshly isolated type II cells (31). Therefore, our results should be interpreted cautiously. Another potential caveat is that experiments were performed at only one time-point following mechanical strain (16 h). Previous microarray studies (9) have shown that induction of gene expression by mechanical forces changes overtime. Thus, we may have missed other genes differentially modulated by strain. Nevertheless, this investigation has identified genes not previously recognized to be induced by force in fetal type II cells.

The present investigations are consistent with previous genome-wide experiments $(11,12,32)$ demonstrating that mechanical strain is a potent stimulus to modulate genes related to apoptosis, cell signaling, transcription, oxidation, extracellular matrix remodeling, and so on. However, our distinct results may be explained by differences in the experimental model system used, type of cells and distension pressure protocol.

In summary, using microarray analysis we have found genes whose expression levels are influenced by mechanical strain. In particular, we have detected genes related to amino acid transporter, amino acid synthesis, and epithelial sodium channel up-regulated by strain. Based on the critical role played by mechanical forces in lung development, the information derived from these experiments may provide further knowledge in understanding the complex interactions between mechanical forces and fetal type II epithelial cells. Characterization of the biologic function of these genes will be an important focus of future studies, which may have an impact on clinical conditions where lung development is impaired, such as extreme prematurity and pulmonary hypoplasia.

Acknowledgments. The authors thank Brenda Vecchio for manuscript preparation and Carl P. Simkevich, Ph.D., for help with the microarray experiments.

\section{REFERENCES}

1. Hooper SB, Wallace MJ 2004 Role of physical, endocrine and growth factors in lung development. In: Harding R, Pinkerton KE, Plopper CG (eds) The Lung: Development, Aging, and the Environment. Elsevier Academic Press, London UK, pp $131-148$

2. Joe P, Wallen LD, Chapin CJ, Lee CH, Allen L, Han VK, Dobbs LG, Hawgood S, Kitterman JA 1997 Effects of mechanical factors on growth and maturation of the lung in fetal sheep. Am J Physiol 272:L95-L105

3. Wirtz HR, Dobbs LG 2000 The effects of mechanical forces on lung functions Respir Physiol 119:1-17

4. Liu M, Post M 2000 Invited review: mechanochemical signal transduction in the fetal lung. J Appl Physiol 89:2078-2084

5. Sanchez-Esteban J, Cicchiello LA, Wang Y, Tsai SW, Williams LK, Torday JS, Rubin LP 2001 Mechanical stretch promotes alveolar epithelial type II cell differentiation. J Appl Physiol 91:589-595

6. Sanchez-Esteban J, Wang Y, Filardo EJ, Rubin LP, Ingber DE 2006 Integrins $\beta 1$, $\alpha 6$, and $\alpha 3$ contribute to mechanical strain-induced differentiation of fetal lung type II epithelial cells via distinct mechanisms. Am J Physiol Lung Cell Mol Physiol 290:L343-L350

7. Sanchez-Esteban J, Tsai SW, Sang J, Qin J, Torday JS, Rubin LP 1998 Effects of mechanical forces on lung-specific gene expression. Am J Med Sci 316:200-204

8. Sanchez-Esteban J, Wang Y, Gruppuso PA, Rubin LP 2004 Mechanical stretch induces fetal type II cell differentiation via an epidermal growth factor receptorextracellular-regulated protein kinase signaling pathway. Am J Respir Cell Mol Biol 30:76-83

9. Chen BP, Li YS, Zhao Y, Chen KD, Li S, Lao J, Yuan S, Shyy JY, Chien S 2001 DNA microarray analysis of gene expression in endothelial cells in response to 24-h shear stress. Physiol Genomics 7:55-63

10. Adam RM, Eaton SH, Estrada C, Nimgaonkar A, Shih SC, Smith LE, Kohane IS, Bagli D, Freeman MR 2004 Mechanical stretch is a highly selective regulator of gene expression in human bladder smooth muscle cells. Physiol Genomics 20:36-44

11. dos Santos CC, Han B, Andrade CF, Bai X, Uhlig S, Hubmayr R, Tsang M, Lodyga M, Keshavjee S, Slutsky AS, Liu M 2004 DNA microarray analysis of gene expression in alveolar epithelial cells in response to TNFalpha, LPS, and cyclic stretch. Physiol Genomics 19:331-342 
12. Chess PR, O'Reilly MA, Toia L 2004 Macroarray analysis reveals a strain-induced oxidant response in pulmonary epithelial cells. Exp Lung Res 30:739-753

13. Patrick J, Natale R, Richardson B 1978 Patterns of human fetal breathing activity at 34 to 35 weeks' gestational age. Am J Obstet Gynecol 132:507-513

14. Tusher VG, Tibshirani R, Chu G 2001 Significance analysis of microarrays applied to the ionizing radiation response. Proc Natl Acad Sci U S A 98:5116-5121

15. Padbury JF, Diah SK, McGonnigal B, Miller C, Fugere C, Kuzniar M, Thompson NL 2004 Transcriptional regulation of the LAT-1/CD98 light chain. Biochem Biophys Res Commun 318:529-534

16. Hummler E, Barker P, Gatzy J, Beermann F, Verdumo C, Schmidt A, Boucher R, Rossier BC 1996 Early death due to defective neonatal lung liquid clearance in alpha-ENaC-deficient mice. Nat Genet 12:325-328

17. Carthew RW, Rubin GM 1990 Seven in absentia, a gene required for specification of R7 cell fate in the Drosophila eye. Cell 63:561-577

18. Scavo LM, Ertsey R, Chapin CJ, Allen L, Kitterman JA 1998 Apoptosis in the development of rat and human fetal lungs. Am J Respir Cell Mol Biol 18:21-31

19. Christensen HN 1990 Role of amino acid transport and countertransport in nutrition and metabolism. Physiol Rev 70:43-77

20. Durante W, Liao L, Reyna SV, Peyton KJ, Schafer AI 2000 Physiological cyclic stretch directs L-arginine transport and metabolism to collagen synthesis in vascular smooth muscle. FASEB J 14:1775-1783

21. Gill DJ, Low BC, Grigor MR 1996 Interleukin-1 beta and tumor necrosis factoralpha stimulate the cat-2 gene of the L-arginine transporter in cultured vascular smooth muscle cells. J Biol Chem 271:11280-11283

22. Hattori Y, Kasai K, Gross SS 1999 Cationic amino acid transporter gene expression in cultured vascular smooth muscle cells and in rats. Am J Physiol 276:H2020 H2028
23. Young SL, Evans K, Eu JP 2002 Nitric oxide modulates branching morphogenesis in fetal rat lung explants. Am J Physiol Lung Cell Mol Physiol 282:L379-L385

24. Ferrara N 2001 Role of vascular endothelial growth factor in regulation of physiological angiogenesis. Am J Physiol Cell Physiol 280:C1358-C1366

25. Balasubramaniam V, Tang JR, Maxey A, Plopper CG, Abman SH 2003 Mild hypoxia impairs alveolarization in the endothelial nitric oxide synthase-deficient mouse. Am J Physiol Lung Cell Mol Physiol 284:L964-L971

26. Jakkula M, Le Cras TD, Gebb S, Hirth KP, Tuder RM, Voelkel NF, Abman SH 2000 Inhibition of angiogenesis decreases alveolarization in the developing rat lung. Am J Physiol Lung Cell Mol Physiol 279:L600-L607

27. Hara A, Chapin CJ, Ertsey R, Kitterman JA 2005 Changes in fetal lung distension alter expression of vascular endothelial growth factor and its isoforms in developing rat lung. Pediatr Res 58:30-37

28. Mager S, Sloan J 2003 Possible role of amino acids, peptides, and sugar transporter in protein removal and innate lung defense. Eur J Pharmacol 479:263-267

29. Olver RE, Walters DV, Wilson SM 2004 Developmental regulation of lung liquid transport. Annu Rev Physiol 66:77-101

30. Tchepichev S, Ueda J, Canessa C, Rossier BC, O’Brodovich H 1995 Lung epithelial Na channel subunits are differentially regulated during development and by steroids. Am J Physiol 269:C805-C812

31. Gonzalez R, Yang YH, Griffin C, Allen L, Tigue Z, Dobbs L 2005 Freshly isolated rat alveolar type I cells, type II cells, and cultured type II cells have distinct molecular phenotypes. Am J Physiol Lung Cell Mol Physiol 288:L179-L189

32. Sozo F, Wallace MJ, Zahra VA, Filby CE, Hooper SB 2006 Gene expression profiling during increased fetal lung expansion identifies genes likely to regulate development of the distal airways. Physiol Genomics 24:105-113 